\title{
FILOSOFIA EM QUADRINHOS \\ uma análise intermidiática de salut Deleuze!
}

\author{
Leonora Soledad Souza e Paula \\ Doutoranda em Literatura Comparada, University of California, San Diego
}

\begin{abstract}
RESU MO
Neste trabalho pretendo discutir o diálogo entre discurso filosófico e narrativa gráfica na obra Salut Deleuze! Resultado de um processo de apropriação da obra Diferença e Repetição (1968) do filósofo Gilles Deleuze, Salut Deleuze! desenvolve-se através de uma experiência de transposição do tema filosófico para a linguagem das histórias em quadrinhos. A repetição deliberada da mesma cena por cinco vezes indica a estrutura narrativa através da qual o enredo é construído e sugere uma criativa reescrita do texto deleuziano ao demonstrar que a repetição é, por natureza, algo sempre novo. Em seguida, proponho observar o processo de intertextualidade com outras obras e discutir o lugar das histórias em quadrinhos no universo de práticas culturais elaboradas através de uma relação intermidiática.
\end{abstract}

PALAVRAS - CHAVE

História em quadrinhos, filosofia, intermidialidade, repetição, diferença

Quando discutimos a produção cultural do momento atual, não podemos nos recusar a considerar o lugar ocupado pelas histórias em quadrinhos no universo de práticas culturais que fazem uso da apropriação de diversas formas de expressão. Os vários extratos textuais, gráficos e culturais contidos nas histórias em quadrinhos contemporâneas refletem os procedimentos intersemióticos e intermidiáticos indispensáveis para a configuração de texto e imagem tal como encontrada na arte produzida no momento presente. Em vista disto, a história em quadrinhos Salut Deleuze! surge como estímulo ao debate envolvendo a experiência de inter-relação entre as mídias. Constituída a partir de um interessante diálogo entre o discurso filosófico e a narrativa gráfico-textual, Salut Deleuze! oferece ao leitor um percurso de leitura que se desdobra em vários níveis de interação, gerando diferentes graus de apreensão. Neste sentido, este trabalho tem como principais objetivos apresentar o texto a ser estudado como uma obra essencialmente intermidiática, identificar a presença do discurso filosófico como interlocutor na construção da obra, apontar a presença de intertextualidades com outras obras e discutir o lugar das histórias em quadrinhos no universo de práticas culturais elaboradas a partir de uma relação intermidiática. 


\section{As HISTÓRIAS EM QUADRINHOS COMO TEXTO MIXMÍDIA}

Qualquer definição das histórias em quadrinhos leva em consideração a relação entre o texto verbal e o texto visual como condição de existência, podendo ou não expandir a interação com outros sistemas de signos. Os estudos da intermidialidade, atentos à necessidade de definição de textos constituídos a partir de relações entre diferentes signos e mídias, oferecem interessantes propostas conceituais, não deixando de incluir os quadrinhos. De acordo com a classificação proposta por Leo H. Hoek, as histórias em quadrinhos podem ser consideradas um texto misto (mixmídia) por excelência, uma vez que tal texto se caracteriza por sua composição em pelo menos duas mídias diferentes, fisicamente inseparáveis, apresentadas como discurso único e experienciado como unidade. ${ }^{1}$ Neste mesmo sentido, Claus Clüver verifica que o texto mixmídia "contém signos complexos em mídias diferentes que não alcançariam coerência ou auto-suficiência fora daquele contexto" ${ }^{2}$ e reconhece que as histórias em quadrinhos fazem parte de um grupo de novas formas de arte criadas e/ou desenvolvidas no século $\mathrm{XX}$, cuja orientação intermidiática as coloca num lugar indefinido no que se refere a abrigos disciplinares.

Portanto, a relação congênita entre dois sistemas de signos fisicamente inseparáveis, apresentados como discurso único e recebidos em simultaneidade, apresentase como uma alternativa eficiente em termos de conceituação das histórias em quadrinhos, o que não encerra o extenso debate sobre o assunto. Contudo, esta alternativa é considerada a via de acesso que nos conduzirá durante o percurso de leitura crítica de Salut Deleuze!

\section{QUADRINHOS CONTEMPORÂNEOS}

Embora consideremos a eficácia da formulação acima, há de se reconhecer uma intensa diversidade no que se refere às formas e gêneros dos quadrinhos. Todavia, levando-se em conta que este estudo se desenvolve acerca de uma publicação contemporânea, as discussões serão aí concentradas.

Neste contexto, observamos que o fenômeno de relação intermidiática presente na construção das histórias em quadrinhos contemporâneas encontra afinidade com os mais recentes paradigmas de produção e criação artísticas, em virtude da interação de diversos sistemas de signos no processo de formação dos textos. Entretanto, reconhecer a contemporaneidade de Salut Deleuze! não se reduz a uma tarefa meramente cronológica, mas implica observar outros aspectos. Para tanto, é necessário identificar algumas características comuns encontradas nessas publicações. Claude Duée, no artigo "Là où le mot se fait image et où l'image se fait mot: Nouvelle bande dessinée et bande dessinée d'avant-garde", apresenta o que ela chama de "nova história em quadrinhos" como uma sofisticada criação cujo processo de constituição parte da apropriação de um pré-

\footnotetext{
${ }^{1}$ HOEK. La transposition intersemiotique, p. 73. Cf. o esquema na p. 30 desta revista.

${ }^{2}$ CLÜVER. Estudos Interartes: Introdução crítica, p. 8.
} 
texto, gerando dois graus de leitura do texto final. Segundo Duée, os artistas que trabalham com este tipo de quadrinhos investem em uma intensa relação com outras manifestações e tomam esta relação de integração como material de criação para suas obras.

Assim, a convivência da nova história em quadrinhos com outras produções culturais se constrói a partir de um criativo processo de ressignifição de recursos empregados anteriormente; nas palavras de Duée, ela "inclui um segundo grau, sob a forma de imitação, alusão, intertextualidade". ${ }^{3}$ Portanto, a transformação desse material atua como recodificação dos signos anteriores em novos elementos de criação utilizados num processo de construção de um novo código que, por definição, é constituído de várias camadas. Esse processo de deslocamento se desenvolve como "uma representação relativamente ampla (mesmo que jamais completa) do texto-fonte composto num sistema sígnico diferente, numa forma apropriada, transmitindo certo sentido de estilo e técnica e incluindo equivalentes de figuras retóricas", ${ }^{4}$ assim como descrito por Clüver. Em outros termos, o processo criativo é elaborado a partir de uma obra e/ou conceito já existente, de maneira que a re-apresentação desse material passe pelo trabalho de ressignificação dos elementos constituintes do texto-fonte e alcance uma outra apresentação.

Como resultado deste processo de construção em camadas, o texto oferece ao leitor pelo menos duas experiências de leitura: a leitura em primeiro grau da narrativa gráfico-textual, assim como apresentada nas páginas da história em quadrinhos; e a leitura em segundo grau do pré-texto presente na narrativa, que requer do leitor um amplo repertório de informações. Lembrando Gérard Genette e a noção de palimpsesto, Duée argumenta que no processo de leitura de uma nova história em quadrinhos, "mesmo que o leitor não tenha conhecimento prévio que possa conduzi-lo ao hipotexto, ele compreende do que se trata". ${ }^{5}$ Logo, é possível reconhecer nessas obras um espaço de interatividade privilegiado não só no que se refere a seu processo de construção como também quanto à participação do leitor, que virá ativar o texto em suas várias dimensões quaisquer que sejam suas experiências de leitura.

De acordo com o exposto acima, é possível aproximar as histórias em quadrinhos contemporâneas do conceito de nova história em quadrinhos, uma vez que ambos os termos compartilham aspectos comuns. Quando falamos de quadrinhos contemporâneos, levamos em conta um texto formado através de um processo de interação entre sistemas de signos desenvolvidos durante a segunda metade do século XX, cuja constituição leva a múltiplos níveis de leitura. Portanto, podemos considerar Salut Deleuze! uma publicação que se aproxima das características dos quadrinhos contemporâneos, uma vez que se observa uma forte relação intersdiscursiva no que se refere a seu processo de construção, gerando diferentes graus de percepção da narrativa.

\footnotetext{
${ }^{3}$ DUÉE. Là où le mot se fait image et où l'image se fait mot, p. 242.

${ }^{4}$ CLÜVER. Estudos Interartes: Conceitos, termos, objetivos, p. 42.

${ }^{5}$ DUÉE. Là où le mot se fait image et où l'image se fait mot, p. 241.
} 


\section{Salut Deleuze!}

Originalmente publicada na revista Strapazin (no. 45/1996), numa primeira versão onde aparecia somente a primeira das cinco repetições que viriam a ser o álbum, Salut Deleuze!, ainda inédita no Brasil, resulta de um trabalho de co-autoria entre Jens Balzer (argumento) e Martin tom Dieck (arte) nessa curiosa experiência gráfico-textual.

Elaborado a partir da apropriação de um conceito chave presente na obra do filósofo francês Gilles Deleuze, sobretudo em Diferença e repetição, Balzer e Dieck construíram, através do diálogo verbo-visual das histórias em quadrinhos, uma interação com o tema filosófico, explorando aspectos narrativos somente possíveis de ser encontrados num texto mixmídia.

Em resumo, o enredo narra o seguinte episódio: o barqueiro dos mundos inferiores conduz Gilles Deleuze, morto recentemente, em sua travessia pelo rio Lete, a fim de levá-lo ao reino dos mortos. Durante o trajeto, Deleuze e seu condutor travam instigantes diálogos acerca de alguns temas filosóficos, dentre eles: rizoma, morte, representação, identidade e, obviamente, diferença e repetição. Ao alcançar o reino de Hades, Deleuze é recebido por seus companheiros Jacques Lacan, Roland Barthes e Michel Foucault que, a cada chegada, propõem ao amigo debates e discussões sobre os mais variados temas e assuntos. ${ }^{6}$ Logo em seguida, o barqueiro retorna ao outro lado do rio e a mesma cena, diferente em texto, se repete não uma, mas quatro outras vezes.

Durante todo o álbum, optou-se por manter o layout básico das páginas sem modificações, isto é, cada página é organizada em quatro quadros de formato e proporções sem grandes variações. No que se refere à estrutura narrativa, algumas vezes observa-se o modelo de continuidade direta entre os quadros no qual o intervalo age como convenção de enquadramento (Fig. 1). Em outras vezes nota-se a técnica de apresentação de cenas em seqüência, unidas através do intervalo, cuja função cumpre um papel narrativo ativado pela participação do leitor, que deve preencher o intervalo

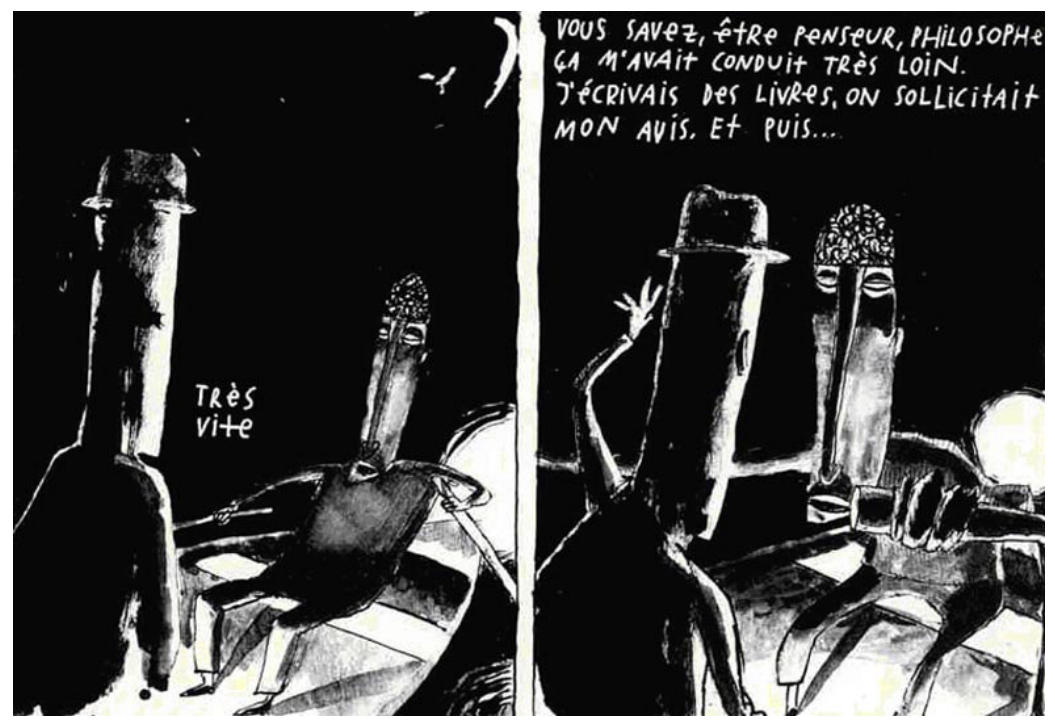

Fig. 1

${ }^{6}$ Tal cena ecoa os famosos diálogos travados nos Diálogos dos Mortos de Luciano (II d.C.) 


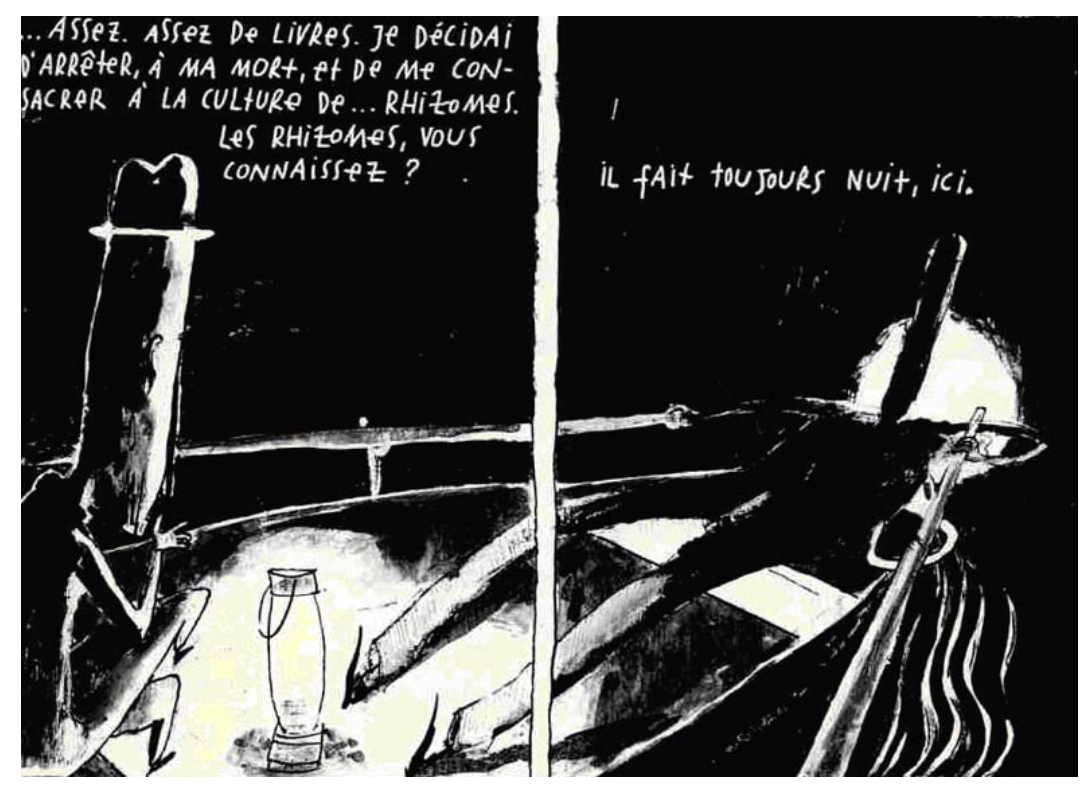

Fig. 2

(Fig. 2). Em relação ao tempo, a predominância do presente em cada cena adquire uma feição de eternidade a partir do momento em que as mesmas são colocadas em repetição; tal noção será discutida no decorrer do estudo.

Quanto à construção das imagens, podemos notar uma total ausência de cores. Ao variar entre luz e sombra, a utilização econômica de uma paleta em branco e preto, com uma visível predominância da última, privilegia o uso deliberado do chiaroscuro como recurso intensificador de uma dramaticidade intimista. A presença da escuridão na maioria das cenas evidencia o espaço privado no qual são travados os diálogos, focalizando o essencial em cada cena e eliminando os possíveis ruídos que poderiam vir a se chocar com a função centralizadora do olhar. Neste sentido, a visão do duplo (chiaroscuro) destaca construções binárias fundamentais, sob as quais são desenvolvidos temas filosóficos essenciais, tais como as relações morte/ressurreição, luz/trevas, público/ privado, realidade/representação. A ausência da luz que, em última instância, define as sombras, ou a eliminação das sombras, da qual surge a luz, sugere uma relação de complementaridade entre os dois conceitos considerados antagônicos; da mesma forma, constrói-se no álbum o diálogo entre a repetição e a diferença.

Em Diferença e repetição, Deleuze procura demonstrar que a repetição é, por natureza, algo sempre novo; cada repetição consiste em um evento particular, pois cada acontecimento ocorre uma única vez e em um tempo distinto, ou seja, em cada repetição há a presença iminente da diferença, pois cada repetição sempre manifesta uma singularidade.

Cientes desta discussão, os autores de Salut Deleuze!, a transformaram em uma manifestação gráfico-textual, explorando as relações conceituais através da repetição do signo visual e da diferença do signo textual. Deste modo, ao criar uma narrativa visual que se repete rigorosamente ao fim de cada uma das nove páginas, em simultaneidade com uma narrativa textual, que se mostra diferente cada vez que a cena se repete, Balzer e Dieck transportam um signo filosófico para os textos verbal e visual que constituem os quadrinhos como texto mixmídia. 
No que se refere ao signo textual presente em Salut Deleuze! notamos que o tema filosófico é citado, mencionado e discutido pelos personagens. Logo no início do álbum, durante a primeira travessia, Deleuze oferece ao barqueiro um livro que contém alguns de seus pensamentos; logo somos informados que se trata de Diferença e repetição, pois, ao início da segunda cena (ou seja, a repetição da primeira) encontramos o livro sobre a mesa do barqueiro. A partir de então, os personagens se entregam ao debate filosófico presente no livro (Fig. 3).

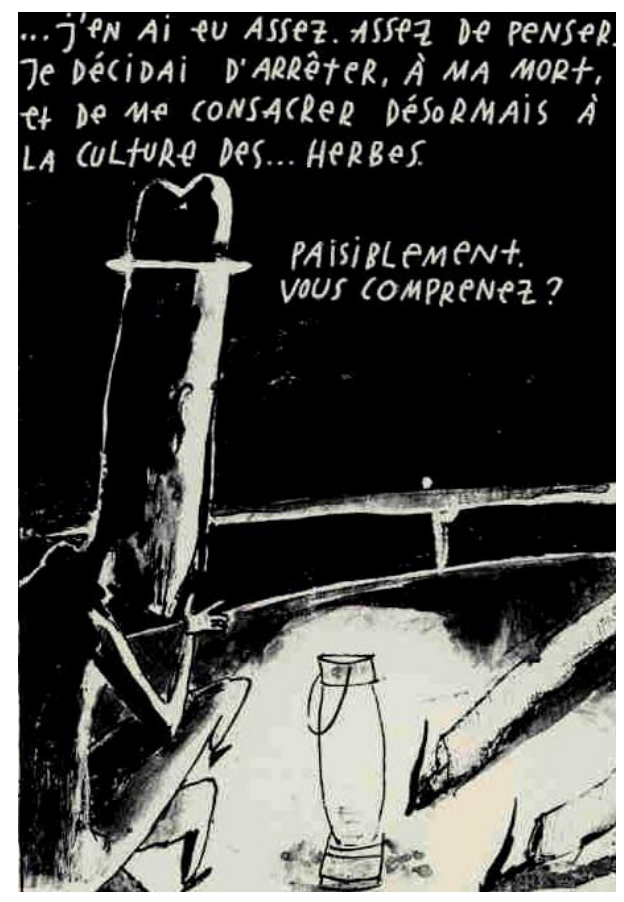

Fig. 3

$\mathrm{O}$ argumento de que tudo se repete frente à eternidade nos conduz diretamente à discussão nietzschiana em torno do conceito de eterno retorno. $\mathrm{O}$ caráter infinito do que retorna se define a partir da diferença gerada pelo movimento de eterna repetição, pois o que retorna não é de maneira alguma idêntico; ao contrário, o que retorna é algo diverso, produzido através do próprio movimento de volta.

Para Deleuze, o retornar é da ordem do devir, ou melhor, o eterno retorno exprime todos os graus de potência manifestados na diferença: "a repetição do eterno retorno consiste em pensar o mesmo a partir do diferente". ${ }^{7}$ A repetição, assim, é a potência própria da diferença. Portanto, é através da repetição que a diferença é alcançada, ou, de outro modo, toda diferença é produzida através de um movimento de repetição consciente, onde o que se repete não é o mesmo, mas algo dessemelhante: "o idêntico não retorna, o mesmo e o semelhante, o análogo e o oposto não retornam. Só a afirmação retorna, isto é, o diferente, o dissimilar". ${ }^{8}$ Logo, no que se diz do eterno retorno, não há repetição de algo idêntico, mas o retorno de algo diferente.

\footnotetext{
${ }^{7}$ DELEUZE. Diferença e repetição, p. 83.

${ }^{8}$ DELEUZE. Diferença e repetição, p. 468.
} 
Certamente, a presença desse conceito no decorrer de todo o álbum indica não só um jogo intertextual com o tema filosófico, como também uma reabilitação sígnica em termos de estratégia narrativa. Em outros termos, o eterno retorno, mais que simples referência textual, é usado como elemento estruturante do conteúdo imagético que busca representar, através das imagens, a diferença existente em cada repetição. Neste sentido, o texto se traduz em imagem e, simultaneamente, a imagem se traduz em texto. Assim, somente um texto construído a partir de uma relação intermidial torna possível uma manifestação tão precisa do discurso filosófico (Fig. 4 e 5).

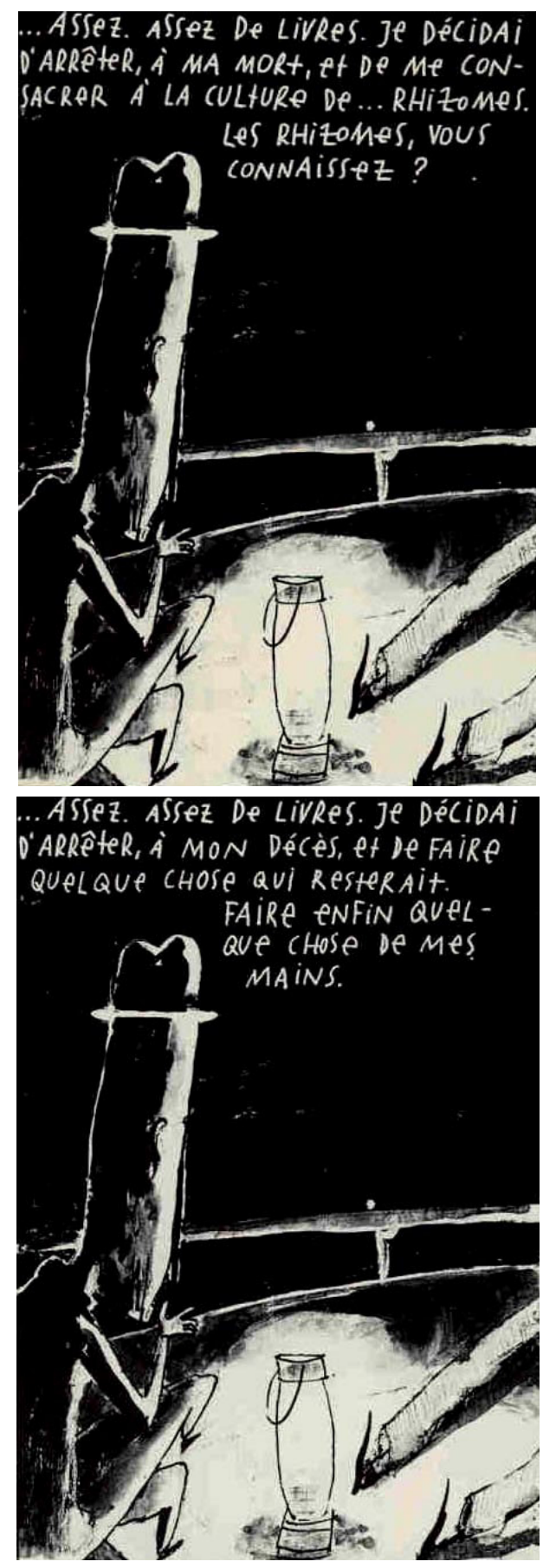

Fig. 4 e 5 
Da mesma forma, Balzer e Dieck discutem a noção de identidade gerada pela diferença. Claramente contrariando o aspecto amnésico do rio Lete (afinal, o rio é conhecido como o rio do esquecimento) tanto o barqueiro quanto Deleuze guardam perfeitas lembranças dos acontecimentos ocorridos durante cada uma das cinco travessias. Contudo, ainda que recorde os diálogos, o barqueiro se recusa a aceitar a idéia de que seu interlocutor seja o mesmo durante todas as travessias. Assim, ele ressalta a particularidade, a peculiaridade do sujeito, ainda que o sujeito seja o mesmo: "Não falo duas vezes com alguém diferente. Se já falei com o senhor alguma vez, é porque o senhor era alguém diferente". 9

De acordo com Ole Frahm no artigo "Weird signs: comics as means of parody", mesmo quando reproduzidas identicamente, as cenas permanecem outras, pois em cada cena os personagens, embora os mesmos, são também outros, assim como argumentado pelo barqueiro na fala citada acima. Quer dizer, em cada cena repetida, ambos os personagens são outros, pois não há identidade fixa, o que existe é a potencialização das identidades:

A identidade se constitui na própria repetição dos signos diferentes. Mais, ainda, mesmo se Deleuze e Caronte fossem descritos de forma idêntica ao longo das nove páginas, seus personagens seriam sempre "outros", pois aparecem em constelações diferentes da história. ${ }^{10}$

A identidade é, portanto, produzida pela diferença. A cada cena há uma identidade produzida através da repetição da cena anterior, que se torna outra a partir do momento em que retorna. Segundo Deluze, "retornar é a única identidade, mas a identidade como potência segunda, a identidade da diferença [...] tal identidade, produzida pela diferença, é determinada como repetição". ${ }^{11}$ Trata-se da impossibilidade da permanência de uma identidade fixa e determinada, o que implica a percepção de um sujeito em constante formação, ou como argumenta o personagem Deleuze, "A identidade como um devir." 12

Em certo sentido, aproximamo-nos do princípio do devir incessante assim como expresso na filosofia de Heráclito: "Não é possível entrar duas vezes no mesmo rio, nem tocar duas vezes uma substância mortal no mesmo estado”. De certa forma, Salut Deleuze! manifesta e estimula tal discussão, pois, embora os mesmos, vemos que homens e rios tornam-se diferentes a cada travessia, e continuarão se transformando a partir de experiências vindouras. Além disso, o incessante movimento de transição no qual se encontram Deleuze e o barqueiro evidencia sua condição de sujeitos à deriva, em constante estado de transformação, revelando as várias potências de identidade. O rio a ser atravessado separa duas condições que somente serão alcançadas quando a travessia se completar, mas, enquanto permanecerem no rio, os sujeitos continuarão fluidos, indefinidos.

\footnotetext{
${ }^{9}$ No original: "Je ne parle deux fois avec personne. Je parle chaque fois avec quelq'un d'autre. Si jamais j'ai déjà parlé avec vous, c'est que vous étiez quelq'un d'autre." BALZER; DIECK. Salut Deleuze!, p. 35-36.

${ }^{10}$ FRAHM. Weird Signs, p. 188.

${ }^{11}$ DELEUZE. Diferença e repetição, p. 83.

${ }^{12}$ No original: "Lidentité comme un devenir." BALZER; DIECK. Salut Deleuze!, p. 35.
} 
Por outro lado, como o barqueiro recebe Deleuze na entrada para o mundo dos mortos e se despede do filósofo em sua última travessia, o texto nos sugere que o barqueiro se dedica à leitura de New Adventures of Incredible Orpheus (Fig. 6). Tal título remete aos leitores os títulos dos quadrinhos de super-heróis conhecidos por enredos nos quais personagens constantemente se envolvem em novas aventuras e se lançam a universos paralelos e viagens no tempo, gerando uma infinidade de seqüências e renovações.

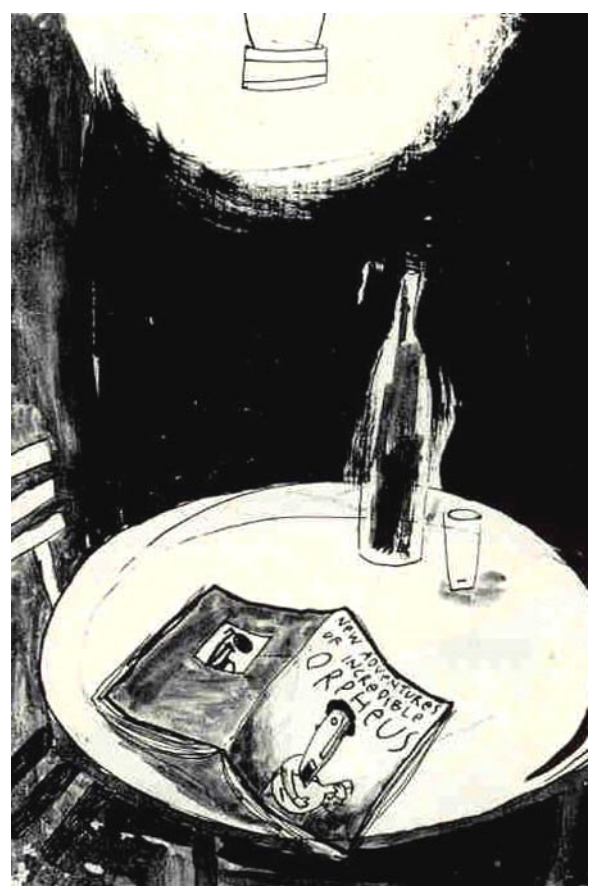

Fig. 6

Em termos narrativos, a presença dessa imagem funciona como um recurso metalingüistico, uma vez que, assim como nas histórias em quadrinhos de super-heróis, as novas aventuras vividas pelo "incrível Orfeu" sugerem a continuidade de outras aventuras já experienciadas pelo protagonista em outros episódios. No caso de Orfeu, a relação intertextual com o mito descrito pela tradição mitológica greco-romana é evidente. Sua descida ao mundo dos mortos é célebre, assim como o é o destino errático ao qual o hábil poeta se lança após o malogro em resgatar sua noiva das profundezas do submundo, para onde, enfim, retorna quando morre. Neste sentido, as novas aventuras de Orfeu poderiam se passar em tempos e lugares distintos daqueles mencionados pelos relatos mitológicos, não dependendo de uma seqüência cronológica linear ou de cenários estritamente relacionados aos eventos do mito original. Em outros termos, seguindo as convenções do gênero dos quadrinhos de super-heróis, Orfeu, como um grande herói do mundo subterrâneo, dotado de poderes sobre-humanos, seria capaz de atravessar dimensões e percorrer longas distâncias espaciais e temporais em suas novas aventuras, assim como sugeridas na publicação da sequência de Salut Deleuze!, Les nouvelles aventures de l'incroyable Orphée (Le Retour de Deleuze).

Porém, em Salut Deleuze!, as várias travessias acabam inevitavelmente conduzindo à experiência final da morte. É explorando esta idéia que o álbum chega ao fim e Deleuze é deixado no mundo dos mortos. A morte impede que haja recomeço sendo, portanto, 
um rompimento com o movimento de volta, e é neste ponto que o barqueiro, na quinta e última travessia, afirma que, mesmo no eterno, há fim.

Neste sentido, a morte finaliza o processo de renovação, pois a continuidade é interrompida e a eterna repetição, enfim, cessa. Para o barqueiro, a morte não conduz ao renascimento; ao contrário, trata-se do fim onde nada recomeça ou renasce, pois a eternidade da morte se apresenta como saída, ruptura com o retorno. De um lado, temos a morte simbólica e, do outro, a morte real e esta prevalece sobre a idéia de que uma equivale à outra. Ou seja, a discussão acerca da eternidade do retorno não se aplica ao fato real da morte de Deleuze no fim do álbum, mas aponta para uma outra narrativa, a da continuação de Salut Deleuze!, constituída a partir dos elementos explorados na primeira experiência.

Assim, Deleuze morre, ou pelo menos não retorna mais uma vez ao barco que atravessa o rio Lete, e desta maneira a transição do personagem se conclui e o eterno deixa de retornar. Em termos narrativos, a morte do personagem funciona como uma estratégia que conduz à finalização do enredo, mas que, de maneira alguma, encerra a discussão, mesmo porque o álbum não nos apresenta uma conclusão, mas sim o encerramento do movimento de travessia. Embora faça a travessia por cinco vezes, Deleuze morre uma única vez e é deixado no mundo dos mortos.

Contudo, a própria leitura de Salut Deleuze! indica um processo contínuo de diferentes leituras das diferentes cenas que se repetem e demanda do leitor não uma, mas várias leituras do álbum, que nunca é o mesmo, pois cada leitura depende da ativação de significados pelo leitor a cada novo percurso de leitura. De acordo com Frahm, nenhum álbum já publicado de Salut Deleuze! é igual ao outro, pois cada um se lê de maneira diferente, como observa Frahm:

As cinco repetições do cruzamento [do rio] antecipam diversas releituras do álbum, sendo que nenhuma delas é igual à outra. E isso também acontece com cada reprodução do álbum "sempre o mesmo", sua reprodução técnica e distribuição para seus leitores. Nenhum álbum é como o outro, pois cada um é publicado e lido em constelações diferentes. ${ }^{13}$

Em última instância, as várias camadas de leitura possíveis serão ou não alcançadas de acordo com o repertório de informações que o leitor disponibiliza no processo de percepção da obra como um todo, ou seja, do signo verbal e signo visual como um único texto, como texto mixmídia.

\section{CONSIDERAÇÕES FINAIS}

Por fim, assim com argumentado anteriormente, é inegável a presença de diferentes apropriações de numerosos temas pertencentes a variadas áreas do conhecimento na recente produção de quadrinhos. No caso de Salut Deleuze!, essa interação é trabalhada de modo notável, gerando diferentes níveis de interação entre o discurso filosófico e a narrativa gráfico-textual. De acordo com a análise proposta neste estudo, é possível

${ }^{13}$ FRAHM. Weird Signs, p. 188. 
sugerir que, ao incorporar o tema filosófico no processo de construção do álbum, os autores de Salut Deleuze! fizeram uso competente da apropriação de um pré-texto, provocando assim o desenvolvimento de seus próprios fazeres artísticos. Portanto, esse fenômeno de interface na criação das histórias em quadrinhos contemporâneas implica um gesto de comunicação com os novos paradigmas de produção da arte, configurando possibilidades inovadoras e estimulantes de interseção entre as artes gráficas e textuais, entre outras.

Contudo, é importante perceber que tal experiência traz consigo questionamentos e problematizações em relação aos próprios paradigmas de produção cultural atual, pois a existência desse tipo de manifestação abala os reconhecidos suportes que ainda abrigam as artes, mesmo em se tratando da produção contemporânea. Trata-se, portanto, de atentar para esse fenômeno como um novo campo de possibilidades de produção criativa que pode, inclusive, vir a gerar outros modelos conceituais para a produção cultural dos próximos momentos.

Enfim, manifestações e bens culturais sempre sofreram influência dos acontecimentos e eventos de seu tempo. $\mathrm{O}$ artista enfrenta hoje uma profusão de informações e materiais com os quais pode trabalhar na criação do objeto artístico, seja ele de que ordem for. Uma multiplicidade de estratégias e recursos é empregada na construção das expressões artísticas atuais, expressões essas que se situam em um incessante movimento de apropriação entre as diversas possibilidades de criação do texto intermidiático, como é o caso das histórias em quadrinhos aqui representadas por Salut Deleuze!

\section{A}

\section{A B S TRACT}

In this essay I discuss the dialogue between the philosophical discourse and the graphic narrative in Salut Deleuze! Clearly related to Gilles Deleuze's book Difference and Repetition (1968), Salut Deleuze! results from the appropriation of the philosophical theme and its transportation to the language of comics. The deliberate repetition of the same scene for five times, keeping the visual text but differing in terms of the verbal text is, in fact, the narrative structure upon which the plot is built, and it is simultaneously a creative analogy to Deleuze's theory, which demonstrates that by its very nature repetition is always new, every repetition being a particular event. In the end I observe the process of intertextuality with other works and discuss comics as belonging to cultural practices involving intermediality.

\section{KEYWORDS}

Comics, philosophy, intermediality, repetition, difference 


\section{REFERÊNCIAS}

BALZER, Jens (r); DIECK, Martin Tom (a). Salut Deleuze! Bruxelles: Fréon Éditions, 1997.

CLÜVER, Claus. Estudos Interartes: Conceitos, termos, objetivos. Literatura e sociedade. São Paulo: FFLCH/USP, n. 2, p. 37-55, 1997.

CLÜVER, Claus. Estudos Interartes: Introdução crítica. Trad. Yung Jung Im e Claus Clüver, rev. Helena Buescu. In: BUESCU, Helena et al. (Org.). Floresta Encantada: Novos caminhos da literatura comparada. Lisboa: Publicações Dom Quixote, 2001, p. 333-362.

DELEUZE, Gilles. Diferença e repetição. (1968). Trad. Luiz B. L. Orlandi e Roberto Machado. Rio de Janeiro: Graal, 1988.

DUÉE, Claude. Là où le mot se fait image et où l'image se fait mot: Nouvelle bande dessinée et bande dessinée d'avant-garde. In: CLÜVER Claus; HOEK, Leo; PLESCH, Véronique (Org.). Orientations: Space /Time /Image / Word. Amsterdam/ New York: Rodopi, 2005, p. 229-243.

FRAHM, Ole. Weird Signs: Comics as means of parody. In: MAGNUSSEN, Anne; CHRISTIANSEN, Hans-Christian (Ed.). Comics and Culture. Copenhagen: University of Copenhagen Press, 2000, p 177-191.

HOEK, Leo H. La transposition intersemiotique: pour une classification pragmatique. In: HOEK, L. H.; MEERHOFF, K. (Ed.). Rhétorique et Image. Amsterdam/Atlanta: Rodopi, 1995, p. 65-80. 